\title{
Charge yield potential of indoor-operated solar cells incorporated into Product Integrated Photovoltaic (PIPV)
}

\author{
N.H. Reich*, W.G.J.H.M. van Sark, W.C. Turkenburg \\ Department of Science, Technology and Society, Copernicus Institute for Sustainable Development and Innovation, Utrecht University, Heidelberglaan 2, 3584 CS Utrecht,
} The Netherlands

\section{A R T I C L E I N F O}

\section{Article history:}

Received 17 February 2010

Accepted 26 July 2010

Available online 21 August 2010

\section{Keywords:}

PIPV

iPV

PV

Design

Solar cell efficiency

STC

\begin{abstract}
A B S T R A C T
Solar cell performance parameters (open circuit voltage, short circuit current, fill factor and efficiency) are derived for different solar cell types for the irradiance range $0.1-1000 \mathrm{~W} / \mathrm{m}^{2}$. Also it is demonstrated how spectral mismatch factors for indoor lighting conditions are calculated. The presented methods and particular results may aid product designers in selecting appropriate solar cells for Product Integrated PV (PIPV) operated indoors and allow for more certainty in energy balance estimations of PIPV design concepts.
\end{abstract}

(c) 2010 Elsevier Ltd. All rights reserved.

\section{Introduction}

The efficiency of photovoltaic (PV) cells is usually reported for only Standard Testing Conditions (STC), which implies $1000 \mathrm{~W} / \mathrm{m}^{2}$ direct normal irradiance intensity, a spectral composition of Air Mass 1.5 (AM 1.5) and temperature of $25^{\circ} \mathrm{C}$. In the indoor environment, however, window glazing that acts as a spectrally selective filter and various emission spectra of artificial light sources imply that the spectral composition diverges greatly from AM 1.5 and also irradiance intensity is generally orders of magnitude lower than one sun. If a Product Integrated PV (PIPV) design implies frequent indoor use, product designers therefore incur a challenging task when attempting to estimate PV efficiencies. Due to the niche market character of PIPV, also no typical charge yields are reported for the many different PV types that could theoretically be incorporated into (electronic) products, which hampers PIPV design processes considerably. In this study, we therefore derive standard solar cell performance parameters (open circuit voltage, short circuit current, fill factor and efficiency) for the broad irradiance intensity range of $0.1-1000 \mathrm{~W} / \mathrm{m}^{2}$. Also it is shown how to calculate spectral mismatch factors to account for indoor irradiance spectra that differ considerably from the AM 1.5 reference case. The presented methods and the particular results may aid product

\footnotetext{
* Corresponding author. Tel.: +31 30253 7611; fax: +31 302537601 .

E-mail address: n.h.reich@uu.nl (N.H. Reich).
}

designers in selecting appropriate solar cells types for PIPV operated indoors and allow for more certainty in energy balance predictions.

\section{Theoretical background}

The operational performance of solar cells is usually characterized by $\mathrm{I}-\mathrm{V}$ characteristic measured under Standard Test Conditions (AM $1.5,1000 \mathrm{~W} / \mathrm{m}^{2}, 25^{\circ} \mathrm{C}$ ). Efficiency $\eta$ is calculated by measured voltage $V_{\mathrm{mp}}$ in [V] and current $I_{\mathrm{mp}}$ in [A] in the point of maximum power (mp) of the current-voltage (IV) curve, which with open circuit voltage $V_{\mathrm{oc}}$ and short circuit current $I_{\mathrm{sc}}$ also defines the Fill Factor (FF) as $\mathrm{FF}=V_{\mathrm{mp}} I_{\mathrm{mp}} / V_{\mathrm{oc}} I_{\mathrm{sc}}$.

$\eta=\frac{P_{\mathrm{max}}}{\mathrm{AP}_{\mathrm{in}}}=\frac{V_{\mathrm{mp}} I_{\mathrm{mp}}}{\mathrm{AP}_{\mathrm{in}}}=\frac{V_{\mathrm{oc}} I_{\mathrm{sc}} \mathrm{FF}}{\mathrm{AP}_{\mathrm{in}}}[\%]$

where $P_{\max }$ is the maximum power generated [W], $A$ is the cell area (usually $\left[\mathrm{cm}^{2}\right]$ ) and $P_{\text {in }}$ the incident power of irradiance (for STC $100 \mathrm{~mW} / \mathrm{cm}^{2}$ if expressed per $\mathrm{cm}^{2}$ or $1000 \mathrm{~W} / \mathrm{m}^{2}$ if expressed per $\mathrm{m}^{2}$ ). See also Fig. 1, where typical values are shown for an arbitrarily selected crystalline silicon (c-Si) PV cell.

Performance deviations due to differing temperatures are usually reported together with STC data, by stated (negative) coefficients $\mathrm{d} V_{\text {oc }} / \mathrm{d} T$ and $\mathrm{dFF} / \mathrm{d} T$. Occasionally also a positive temperature coefficient $d J_{s c} / d T$ of short circuit current densities is considered. However, current increase with temperature is much lower than voltage decrease. 


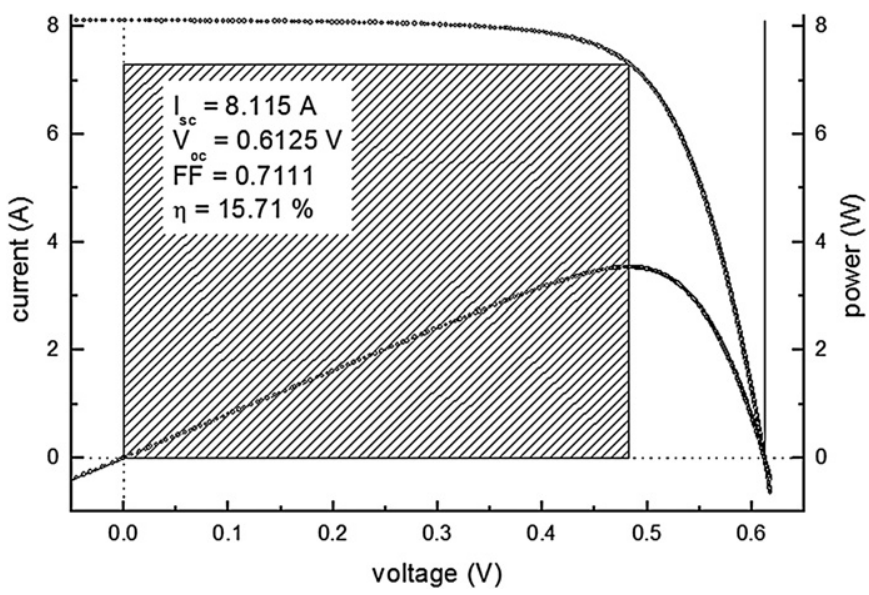

Fig. 1. $I-V$ characteristics of a $15 \times 15 \mathrm{~cm}^{2}$ crystalline silicon solar cell measured at STC. Performance parameters are: $I_{\mathrm{sc}}=8.115 \mathrm{~A}, V_{\mathrm{oc}}=0.6125 \mathrm{~V}, \mathrm{FF}=0.7111$ and $\eta=15.71 \%$.

The PV conversion efficiency further depends considerably on irradiance intensity. This dependency can be modeled with performance data given under STC alone, if one assumes only a single diode as the model-representation of a solar cell. To further simplify the needed modeling here we also omit series- and shuntresistance effects at this point. Assuming zero series and infinite shunt resistances results in the implicit relation of $V_{\mathrm{oc}}$ and short circuit current density $J_{\mathrm{sc}}$ to become:

$V_{\mathrm{oc}}=\frac{k T}{q} \ln \left(\frac{J_{\mathrm{L}}}{J_{0}}+1\right)$

$J_{\mathrm{SC}}=J_{\mathrm{L}}$

in which $J_{\mathrm{L}}$ is the light induced photocurrent density $\left[\mathrm{mA} / \mathrm{cm}^{2}\right]$, which is equal to the short circuit current density $J_{S C}$ (for $J_{S C}>>J_{0}$ ) and $J_{0}$ is the saturation current density of the assumed single diode. Further, $k$ is Boltzmann's constant $\left(1.38 \times 10^{-23} \mathrm{~J} / \mathrm{K}\right), q$ elementary charge $\left(1.602 \times 10^{-19} \mathrm{C}\right)$ and $T$ temperature $[\mathrm{K}]$.

Note that on top of neglecting series and shunt resistance losses the current-voltage characteristic is thereby oversimplified in particular by assuming a single diode only. Usually, see the textbook of Green [1] and references therein, the operation equation needs to be written as:

$$
\begin{aligned}
& I=I_{\mathrm{L}}-I_{01}\left(\exp \frac{q V^{\prime}}{k T}-1\right)-I_{0 n}\left(\exp \frac{q V^{\prime}}{n k T}-1\right)-\frac{V^{\prime}}{R_{\mathrm{sh}}}, \\
& V^{\prime}=V+I R_{\mathrm{se}}
\end{aligned}
$$

in which two diode saturation currents $I_{01}$ and $I_{0 n}$ for two diodes with an ideality factor of 1 and $n$ allow to account for recombination in the space charge regions(s) separately; $V^{\prime}$ is the voltage that for simplicity includes series resistance $R_{\mathrm{se}}$, and $R_{\mathrm{sh}}$ represent shunt resistance. Note that currents in absolute numbers (denoted by $I$ ) and current densities (denoted by $J$ ) can be used interchangeably. Current densities are usually preferred because they ease comparisons of current-characteristics for devices with differing surface areas.

The use of the one diode equation is advantageous in that a dependency of the fill factor with irradiance intensity can be derived, which, subsequently, allows to model irradiance intensity dependent efficiency with no further parameter input. Based upon Eq. (2) in which the open circuit voltage is expressed analytically as a function of intensity, as was first shown by Shockley and Queisser [1], this approach was developed by Green [2], who empirically showed that fill factor losses due to series resistance $R_{\mathrm{S}}$ can be accounted for by
$\mathrm{FF}=\mathrm{FF}_{0}\left(1-r_{\mathrm{s}}\right)$

where $\mathrm{FF}_{0}$ is the fill factor at zero series resistance, and $r_{\mathrm{s}}$ is the normalized series resistance given as $r_{\mathrm{S}}=R_{\mathrm{S}} / R_{\mathrm{CH}}$. The characteristic resistance $R_{\mathrm{CH}}$ is defined as $R_{\mathrm{CH}}=V_{\mathrm{oc}} / I_{\mathrm{Sc}}$, which therefore can be calculated directly from only data given under STC. The fill factor at zero series resistance $\mathrm{FF}_{0}$ is expressed as [1]:

$\mathrm{FF}_{0}=\frac{v_{\mathrm{oc}}-\ln \left(v_{\mathrm{oc}}+0.72\right)}{v_{\mathrm{oc}}+1}$

where the normalized open circuit voltage $v_{\mathrm{oc}}$ is defined as $v_{\mathrm{oc}}=V_{\mathrm{oc}} q k T$. Equations (4) and (5) are accurate for $v_{\mathrm{oc}}>10$ and $r_{\mathrm{s}}<0.4$ [1]. Similarly, shunt resistance effects are estimated:

$\mathrm{FF}=\mathrm{FF}_{0}\left[1-\frac{\left(v_{\mathrm{oc}}+0.7\right)}{v_{\mathrm{oc}}} \frac{\mathrm{FF}_{0}}{r_{\mathrm{sh}}}\right]$,

in which $r_{\mathrm{sh}}=R_{\mathrm{sh}} / R_{\mathrm{CH}}$ is the normalized shunt resistance and the equation is claimed to be valid for $v_{\mathrm{oc}}>10$ and $r_{\mathrm{sh}}>2.5$ [1]. The combined effect of series and shunt resistance can be represented by Eq. (6), if $F F_{0}$ is replaced by FF as given in Eq. (4). Using Eqs. (4)-(6) instead of the two diode approach (Eq. (3)) therefore allows to instantly determine irradiance intensity dependent efficiencies as a function of irradiance level $G$, e.g. $V_{\mathrm{oc}}(G), J_{\mathrm{sc}}(G), \operatorname{FF}(G)$ and $\eta(G)$. Notaly this approach cannot be taken for the two diode model, because solving this equation analytically is impossible. The only input requirement of the much simpler FF-approach, which is based upon the one diode model, is a set of performance parameters $V_{\mathrm{oc}}, J_{\mathrm{sc}}, \mathrm{FF}$, and $\eta$ at a certain irradiance level $G_{0}$, i.e., $V_{\mathrm{oc}}\left(G_{0}\right)$, $J_{\mathrm{sc}}\left(G_{0}\right), \operatorname{FF}\left(G_{0}\right)$, and $\eta\left(G_{0}\right)$. First, the normalized open circuit voltage $v_{\mathrm{oc}}\left(G_{0}\right)$ and characteristic resistance $R_{\mathrm{CH}}\left(G_{0}\right)$ are calculated. Next, under the assumption that $I_{\mathrm{L}}(G)=I_{\mathrm{SC}}(G)$, the current ratio $I_{L}\left(G_{0}\right) / I_{0}\left(G_{0}\right)$ at irradiance level $G_{0}$ is calculated (Eq. (3)), followed by $\mathrm{FF}_{0}\left(G_{0}\right)$ with Eq. (5). Finally, series resistance losses by $R_{\mathrm{s}}\left(G_{0}\right)$ are taken into account, calculated using Eq. (6), and similarly the shunt resistance effects.

On top of the irradiance intensity dependent efficiency also spectral effects need to be considered, because light originating from artificial light sources and also solar energy filtered by window glazing has spectral compositions considerably different from AM 1.5. To do so one needs to combine the Spectral Response of the particular PV cell, denoted $\operatorname{SR}(\lambda)$, with the spectral composition of irradiance, denoted $E(\lambda)$. For reasonable high values of $J_{\mathrm{Ph}}\left(\right.$ i.e., $J_{\mathrm{Sc}}>>J_{0}$ ) the short circuit current density $J_{\mathrm{SC}}$ follows from photocurrent density $J_{\mathrm{Ph}}$ :

$J_{\mathrm{SC}}=J_{\mathrm{Ph}}=\int_{\lambda} E(\lambda) \cdot \mathrm{SR}(\lambda) \cdot \mathrm{d} \lambda\left[\mathrm{mA} / \mathrm{cm}^{2}\right]$

with $E(\lambda)$ the spectral irradiance $\left[\mathrm{Wm}^{-2} \mathrm{~nm}^{-1}\right]$ and $\mathrm{SR}(\lambda)$ the Spectral Response of PV [A/W] at the corresponding wavelengths. The $\operatorname{SR}(\lambda)$ can also be calculated from the Quantum Efficiency $\mathrm{QE}(\lambda)$ :

$\operatorname{SR}(\lambda)=\frac{Q E(\lambda) \cdot q}{h \cdot c}[\mathrm{~A} / \mathrm{W}]$

where $c$ is the light velocity $\left(2.9979 \times 10^{8} \mathrm{~m} / \mathrm{s}\right)$ and $h$ is the Planck constant $\left(6.626 \times 10^{-34} \mathrm{Js}\right)$. The PV current output in the reference

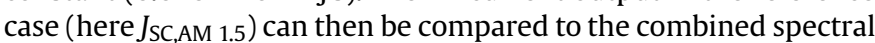
composition of irradiance and PV Spectral Response for the specific cell under specific light situations, i.e., a 'mismatch factor' (MMF) to account for spectral effects that differs from the STC reference case:

$\mathrm{MMF}=\frac{J_{\mathrm{SC}, \mathrm{AM} 1.5}}{\int_{\lambda} E_{\text {normalized }}(\lambda) \cdot \mathrm{SR}(\lambda) \cdot \mathrm{d} \lambda}[\%]$ 
with $E_{\text {normalized }}(\lambda)$ the normalized spectral irradiance intensity with equal overall intensity to the reference case, here STC defined $1000 \mathrm{~W} / \mathrm{m}^{2}$. The practical problem encountered here, however, is that even for a given solar cell of specific type no 'representative' quantum efficiency exists, because $\mathrm{QE}(\lambda)$ reflects solar cell quality rather than that it was a device property to be derived (i.e., it depends on the ability to manufacture efficient cells to achieve high $\mathrm{QE}(\lambda)$, albeit various wavelength regimes in the $\operatorname{SR}(\lambda)$ can be attributed to semiconductor bandgap). We therefore decided to only demonstrate for known, measured $\operatorname{SR}(\lambda)$ and $\operatorname{QE}(\lambda)$ the calculation of spectral mis-match factors (MMF) to account for spectral effects. Here, mono- and multicrystalline silicon (c- and $\mathrm{mc}-\mathrm{Si}$ ) and hydrogenated amorphous silicon (a-Si:H) measured as described elsewhere [3] were used.

\section{Results}

\subsection{Irradiance intensity dependent efficiency}

We decided to model the irradiance intensity dependent efficiencies for those cells that have reported record-efficiencies under STC, as reported bi-annually in the Journal Progress in Photovoltaics: Research and Applications [4], because product designers tend to use this comprehensive overview of PV efficiencies per technology in their design studies [5,6]. The cell characteristics and corresponding efficiencies under STC for these cells are listed in Table 1; irradiance intensity dependent efficiencies for each PV material are shown in Fig. 2. The peak of maximum efficiency as a function of irradiance intensity can be explained by appreciable (apparent) series resistances. The current losses associated to the series resistance decrease with the power of two, whereas photocurrents are lowered linearly. The peak in conversion efficiency occurs between 100 and $500 \mathrm{~W} / \mathrm{m}^{2}$ irradiance intensity for the modeled cells. Regarding the parallel resistance losses, however, we find the used FF-method to fail under low light levels. The modeling requirement $r_{\mathrm{sh}}>2.5$ is not fulfilled for values of $G$ lower than $10-100 \mathrm{~W} / \mathrm{m}^{2}$. For all cell characteristics listed in Table 1 negative FF result between 10 and $100 \mathrm{~W} / \mathrm{m}^{2}$ when accounting for shunt resistance effects using Eq. (6), also when assuming unreasonably high shunt resistances (not shown). For the (wrongly) modeled negative FF also negative efficiencies result, showing this method is inappropriate and cannot be used at low light levels. The performance drop towards weak light shown in Fig. 2 will therefore be much more dramatic particularly for low shunt resistances.

\subsection{Spectral mismatch of indoor spectral irradiance compared to AM 1.5}

To calculate a spectral mismatch with respect to the STC case (AM 1.5 spectrum) one needs to have knowledge on the specific spectral irradiance under which the PV cells are operated at. We therefore arbitrarily selected RGB- and white-LEDs (Light Emitting Diodes) emittance spectra [7], shown in Fig. 3. The spectral irradiance of both light sources shown in Fig. 3 has been scaled such that with the photopic response curve of the human eye [8] the intensity incident onto a surface is 1000 Lux. Note that although the spectral irradiance differs considerably for the two LED types an illuminated area will therefore be perceived as equally bright by the human eye nonetheless.

For the given spectral irradiance one can then calculate a PV current output, if the particular Spectral Response $\operatorname{SR}(\lambda)$ for the particular cell is known. For known $\operatorname{SR}(\lambda)$ this calculation is straightforward, as it only requires a simple multiplication of wavelength resolved irradiance intensities with wavelength resolved current outputs of the particular cell. For the selected cells the Spectral Response $\operatorname{SR}(\lambda)$ is shown in Fig. 4.

The PV output that results for the Spectral Response of the best performing c-Si and a-Si:H cells (Fig. 4) and spectral irradiance data (Fig. 3) at 1000 Lux are listed in Table 2. Conversion efficiency of mc- and c-Si cells, under STC 16-18\%, decreases considerably to as little as $\sim 3-6 \%$ under the artificial LED light, whereas for the aSi:H cells the rather low $\sim 8 \%$ STC efficiency increases to $\sim 20 \%$. The increase in efficiency of a-Si:H under the 1000 Lux LED light is related to two effects. For one, a relatively high voltage is sustained by the a-Si:H cells towards weak light, which can be already inferred from high efficiencies shown in Fig. 2. Furthermore, the larger bandgap of a-Si:H compared to c-Si implies higher efficiency for equal photocurrents generated within each cell type. Note that

Table 1

Solar cell parameters $\eta$, Area, $V_{\mathrm{oc}}, J_{\mathrm{sc}}$, and FF for best cell efficiencies as reported in Green et al. [4] as well as calculated values for $J_{0}$, $\mathrm{FF}_{0}, r_{\mathrm{s}}$ abd $R_{\mathrm{s}}$.

\begin{tabular}{|c|c|c|c|c|c|c|c|c|c|c|}
\hline & \multirow[t]{2}{*}{ Description } & \multirow{2}{*}{$\frac{\eta}{(\%)}$} & \multirow{2}{*}{$\frac{\text { Area }}{\left(\mathrm{cm}^{2}\right)}$} & \multirow{2}{*}{$\frac{V_{o c}}{(V)}$} & \multirow{2}{*}{$\frac{J_{s c}}{\left(\mathrm{~mA} / \mathrm{cm}^{2}\right)}$} & \multirow{2}{*}{$\frac{F F}{\%}$} & \multirow{2}{*}{$\frac{I_{0}}{(\mathrm{~A})}$} & \multirow[t]{2}{*}{$F F_{0}$} & \multirow[t]{2}{*}{$r_{s}$} & \multirow{2}{*}{$\frac{R_{S}}{\left(\mathrm{Ohm} \mathrm{cm}^{2}\right)}$} \\
\hline & & & & & & & & & & \\
\hline \multicolumn{11}{|l|}{ Silicon } \\
\hline $\mathrm{Si}(\mathrm{c})$ & UNSW PERL & 24.7 & 4.00 & 0.706 & 42.2 & 82.8 & $1.920 \times 10^{-13}$ & 0.8477 & 0.02327 & 0.3893 \\
\hline $\mathrm{Si}(\mathrm{mc})$ & FhG-ISE & 20.3 & 1.002 & 0.664 & 37.7 & 80.9 & $2.206 \times 10^{-13}$ & 0.8407 & 0.03768 & 0.6637 \\
\hline $\mathrm{Si}(\mathrm{tft})$ & Uni Stuttgart & 16.6 & 4.017 & 0.645 & 32.8 & 78.2 & $1.613 \times 10^{-12}$ & 0.8372 & 0.06599 & 1.2976 \\
\hline \multicolumn{11}{|l|}{ III-V } \\
\hline GaAs (c) & Kopin, (AlGaAs window) & 25.1 & 3.91 & 1.022 & 28.2 & 87.1 & $5.651 \times 10^{-19}$ & 0.8848 & 0.01558 & 0.5647 \\
\hline GaAs (tf) & Radboud U. & 24.5 & 1.002 & 1.029 & 28.8 & 82.5 & $8.685 \times 10^{-19}$ & 0.8854 & 0.06821 & 2.4369 \\
\hline GaAs (mc) & RTI, Ge substrate & 18.2 & 4.011 & 0.994 & 23.0 & 79.7 & $1.407 \times 10^{-18}$ & 0.8823 & 0.09669 & 4.1787 \\
\hline $\operatorname{InP}(c)$ & Spire, epitaxial & 21.9 & 4.02 & 0.878 & 29.3 & 85.4 & $1.648 \times 10^{-16}$ & 0.8707 & 0.01914 & 0.5734 \\
\hline \multicolumn{11}{|c|}{ Thin film chalcogenide } \\
\hline $\operatorname{CIGS}(\mathrm{cl})$ & NREL, glass & 18.8 & 0.998 & 0.699 & 33.8 & 79.4 & $5.0385 \times 10^{-14}$ & 0.8466 & 0.06213 & 1.2849 \\
\hline CIGS (sm) & Uni Uppsala & 16.6 & 16.0 & 2.643 & 8.35 & 75.1 & $8.855 \times 10^{-13}$ & 0.8401 & 0.10606 & 33.5712 \\
\hline $\mathrm{CdTe}(\mathrm{cl})$ & NREL, glass & 16.5 & 1.032 & 0.845 & 25.9 & 75.5 & $1.353 \times 10^{-16}$ & 0.8669 & 0.12904 & 4.2101 \\
\hline \multicolumn{11}{|c|}{ Amorphous/nanocrystalline Si } \\
\hline $\mathrm{Si}(\mathrm{a})$ & U. Neuchatel & 9.5 & 1.070 & 0.859 & 17.5 & 63.0 & $5.493 \times 10^{-17}$ & 0.8685 & 0.27461 & 13.4796 \\
\hline $\mathrm{Si}(\mathrm{nc})$ & Kaneka ( $2 \mu \mathrm{m}$ on glass) & 10.1 & 1.199 & 0.539 & 24.4 & 76.6 & $2.225 \times 10^{-11}$ & 0.8146 & 0.05967 & 1.3181 \\
\hline \multicolumn{11}{|c|}{ Photo-chemical } \\
\hline
\end{tabular}

Abbreviations are c: crystalline; mc: multicrystalline; tft: thin film transfer; tf: thin film; cl: cell; sm: submodule; a: amorphous; nc: nanocrystalline. 

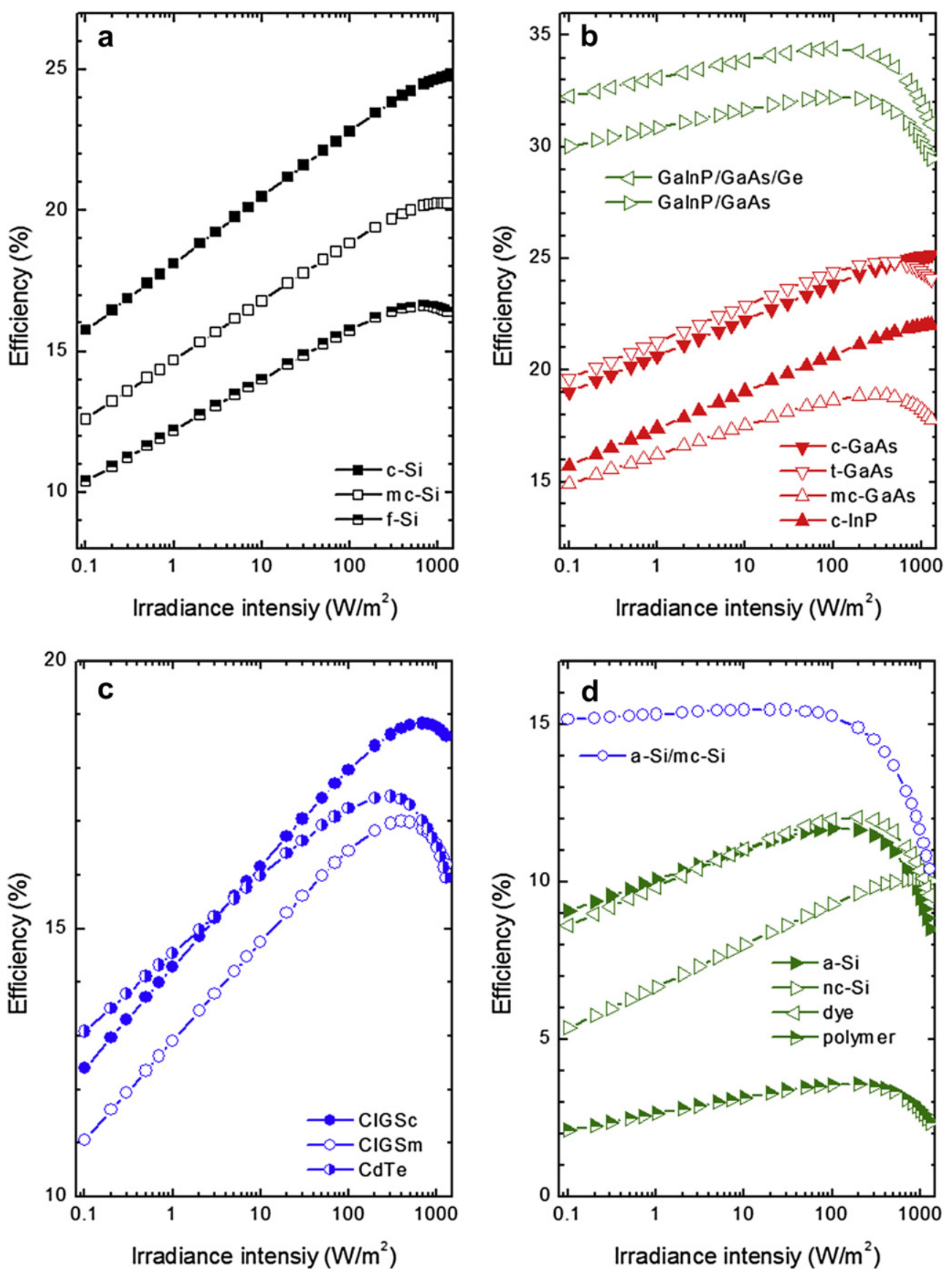

Fig. 2. Calculated irradiance intensity dependent efficiency of various record efficiency solar cells listed in Progress in Photovoltaics: Research and Applications [4].

the selected mc- and c-Si cells have only a somewhat higher light induced photocurrent compared to the a-Si:H cells under LED lighting conditions of 1000 Lux. The 'mis-match factors' of photocurrents under the spectral irradiance of LED light compared with STC defined AM 1.5 can be calculated by the listed short circuit currents and the overall intensity of the LED light, which is $4.16 \mathrm{~W} / \mathrm{m}^{2}$ for the RGB- and $3.71 \mathrm{~W} / \mathrm{m}^{2}$ for the white-LED light. For the a-Si:H cells a MMF of $\sim 2.1$, for mc-Si $\sim 0.82$ and $\mathrm{c}-\mathrm{Si}$ $\sim 0.9$ results.

More generally it is worthwhile to realize that under very low light levels of e.g. 1000 Lux only very little charge can be generated by PV due to the low energy density of light 'as such'. Even a$\mathrm{Si}: \mathrm{H}$ cells, which have a rather high useful voltage output of about
$0.6 \mathrm{~V}$ under this very low intensity, cannot deliver more than $\sim 60 \mu \mathrm{W} / \mathrm{cm}^{2}$ as a power output at 1000 Lux. It can be inferred from various lighting guidelines that the case of 1000 Lux already represents brightly illuminated conditions and that 'minimum' illumination for e.g. corridors is often referred to as $\sim 100$ Lux, which would effectively down-scale the power output of these a$\mathrm{Si}: \mathrm{H}$ cells to as little as $\sim 6 \mu \mathrm{W} / \mathrm{cm}^{2}$. As an example on how little this is, one may assume a standard AA rechargeable battery of $\sim 2$ Wh capacity. To fully charge this battery within 8 h under 100 Lux illumination, assuming no further losses (e.g. related to power electronics of battery under- and over-charge protection, battery efficiency and deviations in IV-operating points from the maximum power point) the a-Si:H cell area would need to be even larger than 


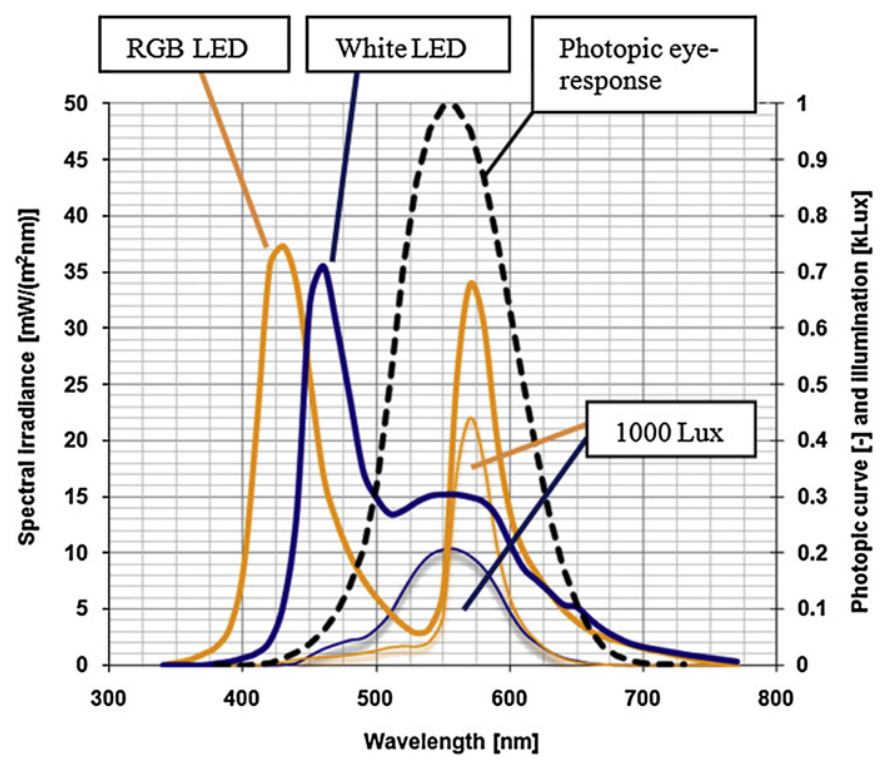

Fig. 3. Spectral irradiance based upon the emittance as reported in [7] RGB- and white-LEDs (light emitting diodes). Note that for the two LEDs two different irradiance intensities $\left(\mathrm{W} / \mathrm{m}^{2}\right)$ under the same illuminance (Lux) result, as listed in Table 2 together with corresponding PV output data.

$\sim 4 \mathrm{~m}^{2}$. Clearly, such PV areas cannot be accommodated into electronic consumer appliances.

\section{Discussion}

We used Fill Factor (FF) expressions to model irradiance intensity dependent efficiency of various PV types. Assuming that the short circuit current is linearly dependent on irradiance intensity $G$ (thus assuming: $I_{\mathrm{sc}}(G)=a G$ ) allows to calculate the whole set of parameters $V_{\mathrm{oc}}(G), R_{\mathrm{CH}}(G), r_{\mathrm{s}}(G), v_{\mathrm{oc}}(G), \mathrm{FF}_{0}(G), \mathrm{FF}(G)$ and $\eta(G)$ as a function of irradiance intensity $(G)$, using STC parameter sets alone. However, we find this 'FF-method' to fail below $10-100 \mathrm{~W} / \mathrm{m}^{2}$ irradiance intensity, as the FF model requirement $r_{\mathrm{sh}}>2.5$ is no longer fulfilled and modeled FF and efficiencies even become negative when accounting for shunt resistance losses. The performance drop caused by low shunt resistances will therefore be much more dramatic toward low irradiance intensities $\left(<100 \mathrm{~W} / \mathrm{m}^{2}\right)$ than the FF model based results (shown in Fig. 2). These irradiance intensity dependent efficiencies, calculated for record efficiency solar cells, nonetheless give a good indication on efficiency ranges one may consider as the upper limit for given STC cell properties, because the different orders of magnitudes of diode saturation currents and thereto related voltage decrease toward weak light is accurately accounted for. A further decrease owed to (low) shunt resistances, however, needs to be taken into account, particularly if shunts have appreciable current drain close to corresponding voltages at weak light. Future research is needed here to ascertain attainable efficiencies of PV under low light situations for 'realworld' PV devices. Although a previous study already addressed measured low light performance of various PV types here, unfortunately no diode model parameter sets and in particular no shunt resistances were presented [9]. Measuring PV devices under low light, however, is not always possible or desired, as it not only can take a considerable effort to obtain cell samples from various technologies but also the measurement of PV weak light performance is not standard and quite cumbersome [9]. Here, the presented FF-modeling approach may aid product designers in (pre-) selecting appropriate PV types. In particular cells of type a-Si:H are of interest here, due to their good match of Spectral Response with (energy saving) artificial light. Here, we demonstrated how to calculate a light induced photocurrent based upon Spectral Response of PV and spectral irradiance of incident light, by a simple wavelength resolved multiplication. One may argue, however, that the spectral response is usually measured under a bias light intensity that is much higher than e.g. 1000 Lux used here, and that the electric field in a-Si:H cells depends on both the spectral composition and irradiance intensity. This may imply that a simply multiplication would yield wrong results. Related research and the operating principle of a-Si:H cells, however, shows that these concerns should not cause large deviations. For one, in a-Si:H cells there exists an electric field in the entire intrinsic layer, which implies charge carriers are collected by drift rather than diffusion. Due to the very low diffusion length of free charge carriers within a$\mathrm{Si}: \mathrm{H}$ cells this is actually a required device property. More detailed descriptions on operating principles can be found in literature, concerning a-Si:H cells as presented by Crandall [10] and for a-Si:H and a-SiGe cells [11] and more recently for CdTe and CdS [12] by Hegedus. Here, Hegedus showed in particular that the flatband voltage $\left(V_{\mathrm{fb}}\right)$ depends on illumination intensity and spectrum, hence $V_{\mathrm{fb}}$ limits $V_{\mathrm{oc}}$ rather than $J_{0}$ such as in 'typical' solar cells. The relative deviation of $4 \%$ rel in modeled $V_{\text {oc }}$ due to changing bias light as reported by Hegedus, however, is related to a saturation of the photocurrent. As such a saturation of the photocurrent occurs towards higher intensities it is of no relevance for the case of weak light.
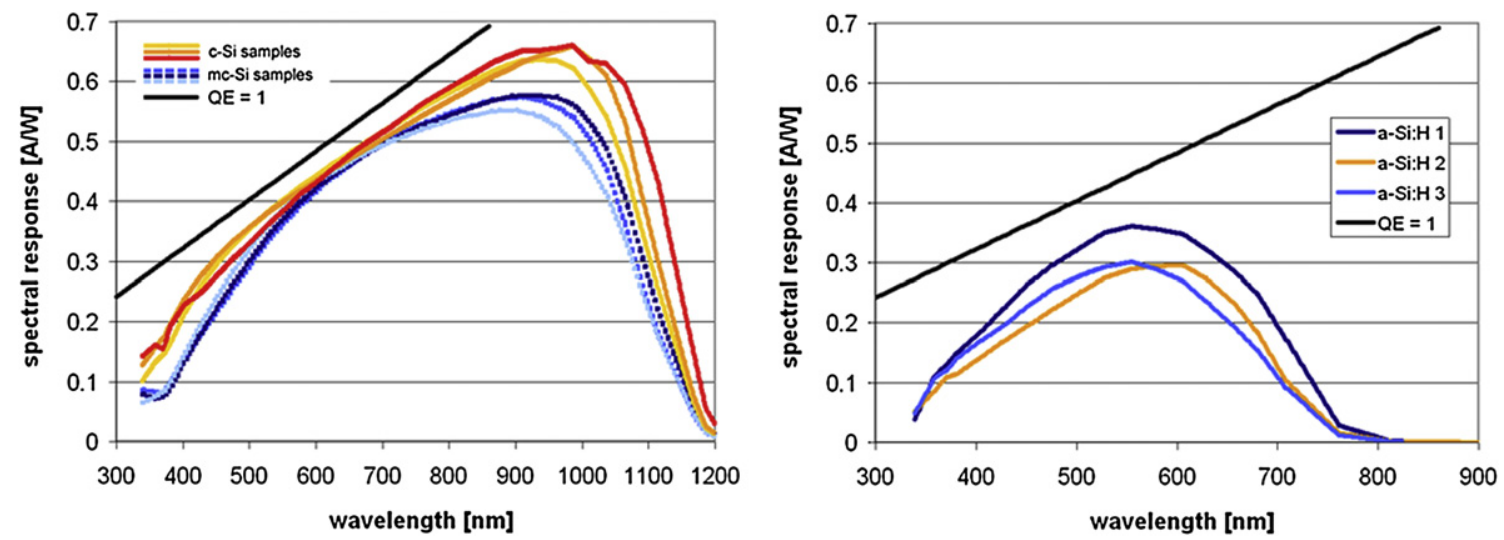

Fig. 4. Measured spectral response of (a) various mono- and multicrystaline silicon cells and (b) hydrogenated amorphorous silicon cells (a-Si:H), see [3]. 
Table 2

Solar cell performance parameters under STC and artificial lighting conditions (at 1000 Lux illumination for $4.16 \mathrm{~W} / \mathrm{m}^{2} \mathrm{RGB}-$ and $3.71 \mathrm{~W} / \mathrm{m}^{2}$ white-LED light).

\begin{tabular}{|c|c|c|c|c|c|c|c|c|c|c|c|}
\hline & \multicolumn{3}{|c|}{$J_{\mathrm{sc}}\left[\mu \mathrm{A} \& \mathrm{~mA} \mathrm{~cm}^{-2}\right]$} & \multicolumn{3}{|c|}{$V_{\mathrm{oc}}[\mathrm{V}]$} & \multicolumn{3}{|c|}{$\mathrm{FF}[-]$} & \multicolumn{2}{|l|}{ Efficiency } \\
\hline & LED1 $\mu \mathrm{A}$ & LED2 $\mu \mathrm{A}$ & $\mathrm{STC} \mathrm{mA}$ & LED1 & LED2 & STC & LED1 & LED2 & STC & LED $1 / 2$ & STC \\
\hline $\mathrm{a}-\mathrm{Si}: \mathrm{H}$ & 118 & 113 & 13.5 & 0.67 & 0.67 & 0.82 & 0.68 & 0.68 & 0.7 & $\sim 19-21$ & 7.7 \\
\hline $\mathrm{c}-\mathrm{Si}$ & 138 & 94 & $\sim 37$ & 0.4 & 0.4 & $\sim 0.7$ & 0.35 & 0.35 & $\sim 0.8$ & $5.3-5.6$ & 18.2 \\
\hline $\mathrm{mc}-\mathrm{Si}$ & 119 & 86 & $\sim 35$ & 0.3 & 0.3 & $\sim 0.6$ & 0.35 & 0.35 & $\sim 0.8$ & $3.6-3.7$ & 16.8 \\
\hline
\end{tabular}

\section{Conclusions}

We used Fill Factor (FF) expressions to model irradiance intensity dependent efficiency of various PV types and presented how to calculate PV power output with spectrally resolved irradiance and PV performance data. Here, we show in particular that a-Si:H cells with only $\sim 8 \%$ efficiency under Standard Testing Conditions (STC) show up to $\sim 20 \%$ efficiency under energy efficient lighting, which is contrary to mc- and c-Si cells, which show very large efficiency under STC of $\sim 16-18 \%$ but only $\sim 3-6 \%$ under energy efficient LED lighting. The presented methods and particular results will aid product designers in selecting appropriate solar cells for Product Integrated PV (PIPV) operated indoors and allow for more certainty in energy balance estimations of PIPV design concepts.

\section{Acknowledgements}

We would like to acknowledge financial support in part from the Netherlands Organization for Energy and the Environment (NOVEM), the Netherlands Organization for Scientific Research (NWO) within the framework of their joint program on Stimulating Energy Research through the project SYN-Energy [8].

\section{References}

[1] Shockley W, Queisser HJ. Detailed balance limit of efficiency of $\mathrm{p}-\mathrm{n}$ junction solar cells. J Appl Phys 1961;32:510.

[2] Green MA. Solar cells; operating principles, technology and systems application. Englewood Cliffs, NJ, USA: Prentice-Hall; 1982.
[3] Reich $\mathrm{NH}$, Van Sark WGJHM, Alsema EA, Kan SY, Silvester S, Van der Heide ASH, et al. Weak light performance and spectral response of different solar cell types. In: Hoffmann W, Bal J-L, Ossenbrink H, editors. Proceedings of 20th European photovoltaic solar energy conference. WIP Renewable Energies Munich; 2005

[4] Green MA, Emery K, King DL, Hisikawa Y, Warta W. Solar cell efficiency tables (version 33). Prog Photovolt Res Appl 2009;17:85-94.

[5] Reinders AHME, de Boer A. Product-Integrated PV - innovative design methods for PV-powered products. In: Lincot D, Ossenbrink H, Helm P, editors. Proceedings of 23rd European photovoltaic solar energy conference and exhibition. Valencia, Spain: WIP-Renewable Energies, Munich, Germany; 2008. p. 3321-4

[6] Alsema EA, Reich NH, van Sark WGJHM, Kan SY, Silvester S, Veefkind M, et al. Towards an optimized design method for PV-powered consumer and professional applications - the syn-energy project. In: Hoffmann W, Bal J-L, Ossenbrink H, Palz W, Helm P, editors. Proceedings of twentieth European photovoltaic solar energy conference. Barcelona, Spain: WIP, Munich, Germany; 2005. p. 1981-4.

[7] Hamamatsu mini-spectrometer RC series C9407MA and C9409MA datasheet. accessible under, www.sales.hamamatsu.com/OEM-MS [accessed 12.02.10].

[8] CIE. Commission internationale de l'Eclairage proceedings. 1924, accessible via. Cambridge: Cambridge University Press, http://en.wikipedia.org/wiki/ Luminosity_function; 1926 [accessed 12.02.10]. Report.

[9] Randall JF, Jacot J. Is AM 1.5 applicable in practice? Modelling eight photovoltaic materials with respect to light intensity and two spectra. Renewable Energy 2003;28(12):1851-64.

[10] Crandall RS. Defect relexation in amorphous silicon: streched exponentials, the Meyer-Neldel rule, and the Staebler-Wronski effect. Phys Rev B 1991;43 (5):4057-70.

[11] Hegedus S. Current-voltage analysis of a-Si and a-SiGe solar cells including voltage-dependent photocurrent collection. Prog Photovolt Res Appl 1997;5 (2):151-68.

[12] Hegedus S, Desai D, Thompson C. Voltage dependent photocurrent collection in CdTe/CdS solar cells. Prog Photovolt Res Appl 2007;15(7): 587-602. 